\title{
Mechanism of Broccoli-Mediated Verticillium Wilt Reduction in Cauliflower
}

\author{
K. G. Shetty, K. V. Subbarao, O. C. Huisman, and J. C. Hubbard
}

First, second, and fourth authors: Department of Plant Pathology, University of California, Davis, c/o United States Agricultural Research Station, 1636 E. Alisal Street, Salinas 93905; and third author: Department of Environmental Science, Policy and Management, Division of Insect Biology, University of California, Berkeley 94720.

Accepted for publication 29 November 1999.

\begin{abstract}
Shetty, K. G., Subbarao, K. V., Huisman, O. C., and Hubbard, J. C. 2000. Mechanism of broccoli-mediated Verticillium wilt reduction in cauliflower. Phytopathology 90:305-310.

Broccoli is resistant to Verticillium dahliae infection and does not express wilt symptoms. Incorporation of broccoli residues reduces soil populations of $V$. dahliae. The effects of broccoli residue were tested on the colonization of roots by $V$. dahliae, plant growth response, and disease incidence of both broccoli and cauliflower in soils with different levels of $V$. dahliae inoculum and with or without fresh broccoli residue amendments. The three soils included a low-Verticillium soil, a high-Verticillium soil, and a broccoli-rotation soil (soil from a field after two broccoli

sclerotia per $\mathrm{g}$ of soil, respectively. Cauliflower plants in broccoli-amended high-Verticillium soil had significantly $(P \leq 0.05)$ lower wilt incidence and severity than did plants in unamended soil. An immunohistochemical staining assay utilizing a monoclonal antibody specific to $V$. dahliae was used to determine colonization of the root cortex. Despite the absence of wilt symptoms, broccoli roots were colonized by V. dahliae. In high-Verticillium soil, the broccoli residue amendment caused a marked reduction in colonization rate of $V$. dahliae per unit of inoculum on both cauliflower and broccoli roots. In addition to its detrimental effects on the viability of microsclerotia in soil, broccoli residue may also have an inhibitory effect on the root-colonizing potential of surviving microsclerotia.
\end{abstract} crops) with an average of 13,38 , and below-detectable levels of micro-
Additional keywords: crucifer residue, cultural control, root colonization.
Verticillium dahliae Kleb., the causal agent of vascular wilt on a range of economically important crops, is a soilborne plant pathogen distributed over a wide range of geographic locations. The pathogen forms microsclerotia in senescent and dead host plant tissues that can survive in the soil for many years (28). Germination of microsclerotia is induced by root exudates from host plants. The infection process starts with colonization and penetration of the root cortical tissue. The fungus then advances inter- or intracellularly through the cortex tissue and enters the vascular tissue. Thereafter, the infection spreads systemically through the xylem, and wilt symptoms ensue.

Cauliflower is an important vegetable crop that is grown yearround in central coastal California on 15,600 ha. Cauliflower has an annual gross value of more than $\$ 158$ million. In recent years, Verticillium wilt has become a serious threat to the coastal California cauliflower crop (19). Verticillium wilt in cauliflower ultimately results in small size and poor quality of harvested heads (19).

Although broccoli and cauliflower are related within the genus Brassica, they differ markedly in their response to infection by $V$. dahliae. Whereas cauliflower is susceptible to a majority of $V$. dahliae isolates from vegetable crops (33), broccoli is resistant to cauliflower and cabbage isolates of $V$. dahliae and is immune to all other isolates of $V$. dahliae (R. G. Bhat and K. V. Subbarao, unpublished data). In greenhouse inoculations, the cauliflower isolates of $V$. dahliae cause limited superficial infections on broccoli with very restricted vascular discoloration. Both in greenhouse and field experiments, amendment of soil with broccoli residues resulted in significant reductions in the numbers of $V$. dahliae microsclerotia in soil and incidence of wilt in the following cauliflower crop $(34,35,38)$.

Corresponding author: K. V. Subbarao; E-mail address: kvsubbarao@ucdavis.edu

Publication no. P-2000-0126-04R

(C) 2000 The American Phytopathological Society
In addition to the suppressive effects of broccoli crop residues on microsclerotia of $V$. dahliae in soil, resistance to Verticillium wilt in broccoli is equally crucial to its use as a rotation crop in the management of Verticillium wilt of cauliflower. Very little is known about the activity of $V$. dahliae on the root cortical surface (rhizoplane) of broccoli or cauliflower in the presence or absence of broccoli residue amendment. Experimental analysis of $V$. dahliae root colonization patterns on a resistant and a susceptible plant would provide a critical comparison for studying the mechanisms underlying the broccoli residue effect.

$V$. dahliae primarily colonizes the rhizoplane of the host plant $(10,16)$. However, other soil fungi that are saprophytic in nature also colonize the rhizoplane in a similar manner (16). This presents a difficult technical problem in quantification of colonies of $V$. dahliae on roots. An immunoassay based on a monoclonal antibody specific for $V$. dahliae (14) was found to be superior to the bioassay on semiselective media (O. C. Huisman and J. R. Davis, unpublished data). It should be possible, therefore, to analyze colonization of roots by this pathogen more specifically.

The objective of this study was to elucidate the mechanisms of broccoli-mediated Verticillium wilt reduction in cauliflower. The differential response of cauliflower and broccoli to amendment with broccoli residues was studied in a greenhouse experiment, using soils containing different population densities of microsclerotia. Comparative observations on host growth and wilt incidence were made and progression of cortical surface infection on cauliflower and broccoli roots was studied by employing the $V$. dahliae-specific monoclonal antibody-based immunohistochemical staining technique.

\section{MATERIALS AND METHODS}

Treatments and experimental design. A greenhouse experiment was set up using soil (Antioch sandy loam/sand, 46\%; silt, $43 \%$; clay, 9\%; and organic matter, $1.8 \%$; $\mathrm{pH} 6.1$ ) from a cauliflower field experiment with various levels of microsclerotia of $V$. dahliae, with and without a history of broccoli rotation (38). The 
soil was naturally infested with $V$. dahliae inoculum (predominantly cauliflower isolates) derived from the repeated cauliflower crop and Verticillium wilt-incidence history. In addition, the soil was also artificially infested with $V$. dahliae microsclerotia (cauliflower isolate). The three soils used were low-Verticillium (LV) soil (soil with an average of $13 \mathrm{~V}$. dahliae microsclerotia per g of soil), highVerticillium (HV) soil (soil with an average of $38 \mathrm{~V}$. dahliae microsclerotia per $\mathrm{g}$ of soil), and broccoli-rotation (BB) soil (soil initially similar to HV soil but microsclerotia reduced to below-detectable levels after two broccoli crops). The six soil treatment combinations consisted of the three soils alone and each soil amended with broccoli residue. Each soil treatment combination was divided into two sets, one planted with cauliflower and the other with broccoli. Ten 25-cm-diameter pots were used for each soil treatment-plant combination, and the pots were set up in a completely randomized design in the greenhouse $\left(25 \pm 3^{\circ} \mathrm{C}\right)$. For the broccoli-amended treatments, coarsely chopped fresh broccoli pieces of the aboveground portion of broccoli plants was mixed into the soil at $8.66 \%$ of soil dry weight. The amount of residue had been previously calculated as the level incorporated into a commercial broccoli field after harvest (34). Pots were filled for all soil treatments and the soil was kept moderately moist for 3 weeks in the greenhouse. Seeds of broccoli (cv. Greenbelt) and cauliflower (cv. White Rock) were planted. After emergence, plants were thinned to retain one plant per pot and fertilized biweekly at recommended rates.

Sampling and immunohistochemical assay. Soil samples were collected at 4, 6, and 12 weeks after transplanting from a depth of up to $10 \mathrm{~cm}$ using a 2-cm-diameter soil core. Samples were taken approximately $3 \mathrm{~cm}$ away from the edge of the pot to minimize edge effects. The first and second soil samples were drawn from 5 pots of the total 10, and final sampling occurred from all 10 pots. The roots were extracted from the soil by wet sieving, carefully washed free of soil, and fixed in neutral buffered formalin (Sigma Chemical Co., St. Louis). At final sampling (12 weeks), plant height, number of leaves, and shoot and root dry matter were also recorded for each plant. The severity of the Verticillium infection was rated as percent vascular discoloration (19). Soil samples from each pot were collected, air-dried, and assayed for the number of $V$. dahliae microsclerotia by plating onto NP-10 medium using the modified Anderson sampler technique (8). The experiment was repeated once.

Fixed roots were cut into small pieces of approximately 1 to $2 \mathrm{~cm}$ in length, mixed well, and a small subsample or the whole sample was transferred to screw-cap vials containing phosphate buffer. The vials were placed in a boiling water bath to inactivate any endogenous phosphatase enzymes present. After cooling, the root pieces were transferred to polystyrene plate wells (six by four wells per plate). During each run, each plate included a positive control root sample well (highly colonized potato or cotton roots from a $V$. dahliae-infested field).

$V$. dahliae colonies on the roots were detected with a modified immunohistochemical staining assay (14) using a monoclonal anti-

TABLE 1. Soil populations of Verticillium dahliae (number of microsclerotia per gram of dry soil) in different treatment combinations

\begin{tabular}{|c|c|c|}
\hline Treatment, amendment ${ }^{y}$ & Initial $^{\mathrm{Z}}$ & 12 weeks after planting \\
\hline \multicolumn{3}{|l|}{ LV soil } \\
\hline Broccoli & $13 \pm 1$ & $4 \pm 0.0$ \\
\hline No broccoli & $13 \pm 1$ & $8 \pm 2.0$ \\
\hline \multicolumn{3}{|l|}{ HV soil } \\
\hline Broccoli & $38 \pm 5.5$ & $12 \pm 3.7$ \\
\hline No broccoli & $38 \pm 5.5$ & $29 \pm 4.7$ \\
\hline \multicolumn{3}{|l|}{ BB soil } \\
\hline Broccoli & 0 & 0 \\
\hline No broccoli & 0 & 0 \\
\hline
\end{tabular}

${ }^{y} \mathrm{LV}=$ soil with $13 \mathrm{~V}$. dahliae microsclerotia per $\mathrm{g}$ of dry soil; $\mathrm{HV}=$ soil with $38 \mathrm{~V}$. dahliae microsclerotia per $\mathrm{g}$ of dry soil; and $\mathrm{BB}=$ soil with undetectable $V$. dahliae microsclerotia.

${ }^{\mathrm{z}}$ Soil sampled prior to the incorporation of broccoli residues. body highly specific to $V$. dahliae. Following the initial treatment with blocking buffer, the root samples were incubated first with $V$. dahliae-specific rabbit monoclonal antibody and then with enzymeconjugated goat anti-rabbit immunoglobulin G antibody. Finally, the root samples were stained with substrate buffer solution containing Fast Blue BB salt (Sigma Chemical Co.). The stained root pieces from each sample were carefully transferred to labeled screwcap vials containing phosphate buffer with $0.2 \%$ sodium azide as a preservative.

The stained roots from each sample were randomly placed on a plastic petri plate marked with $1 \times 1-\mathrm{cm}$ grids. A film of $90 \%$ glycerol solution was maintained on the surface of each petri plate, which firmly held the root pieces in position and prevented drying during observation. The total root length was determined using the line intersect method of Tennant (36), and the number of $V$. dahliae colonies was expressed as number of colonies per $m$ of root. Under a stereomicroscope, the total number of intersection points for the whole of the stained sample was determined. Later, each root piece was individually observed under higher magnification on all sides for dark blue-stained colonies of $V$. dahliae. The $V$. dahliae colonies on the root surface without immediate hyphal connections were scored as separate colonies. On average, the length of root per plant examined from all of the treatments ranged from $1.2 \mathrm{~m}$ (for the 4-week sample) to $3.7 \mathrm{~m}$ (for the 12-week sample).

Formation of microsclerotia in broccoli. A greenhouse experiment was conducted to determine the development of microsclerotia on broccoli plant roots following a root-dip inoculation. Five 30-day-old broccoli (cv. Patriot) transplants were washed free of debris before inoculation and planting. Conidial suspensions were prepared from 25-day-old cultures of the cauliflower isolate of $V$. dahliae (VdBob70) by adding $10 \mathrm{ml}$ of sterile distilled water to a potato dextrose agar plate of $V$. dahliae and scraping the cultures with a rubber spatula. Using a hemacytometer, the density of conidia in the inoculum was adjusted to $10^{7}$ conidia per ml.

The roots of transplants were trimmed by removing a $2.5-\mathrm{cm} \mathrm{sec-}$ tion from the tips of roots. They were then dipped in the conidial suspension for $5 \mathrm{~min}$ and planted individually in autoclaved sand in 25 -cm-diameter pots. The plants were grown on greenhouse benches $\left(25 \pm 3^{\circ} \mathrm{C}\right)$. After 12 weeks, the aboveground portion of the plants was cut off and the root system was left in the pot for an additional 8 weeks. The roots were washed free of sand, gently blotted dry, and observed under a stereomicroscope for the presence of microsclerotia. Roots were air-dried for 2 weeks and again observed for the presence of microsclerotia on root tissue.

Data analyses. Differences between treatments for cauliflower and broccoli plant height, number of leaves, vascular discoloration, and shoot and root biomass were determined by analysis of variance, and means were compared by the least significant difference

TABLE 2. Effect of soil treatment and broccoli amendment on cauliflower growth and biomass and on Verticillium dahliae-induced vascular discoloration

\begin{tabular}{|c|c|c|c|c|c|}
\hline $\begin{array}{l}\text { Treatment, } \\
\text { amendment }^{\mathrm{x}}\end{array}$ & $\begin{array}{l}\text { Plant } \\
\text { height } \\
(\mathrm{cm})\end{array}$ & $\begin{array}{l}\text { No. of } \\
\text { leaves }\end{array}$ & $\begin{array}{l}\text { Shoot dry } \\
\text { weight } \\
\text { (g) }\end{array}$ & $\begin{array}{l}\text { Root dry } \\
\text { weight } \\
\text { (g) }\end{array}$ & $\begin{array}{c}\text { Vascular } \\
\text { discoloration } \\
(\%)^{\mathrm{y}}\end{array}$ \\
\hline \multicolumn{6}{|l|}{ LV soil } \\
\hline Broccoli & $32.9 \mathrm{a}^{\mathrm{z}}$ & $15.6 \mathrm{ab}$ & $34.63 \mathrm{a}$ & $8.03 \mathrm{a}$ & $10 \mathrm{~b}$ \\
\hline No broccoli & $27.7 \mathrm{~b}$ & $12.3 \mathrm{c}$ & $29.73 \mathrm{~b}$ & $6.85 \mathrm{~b}$ & $0 \mathrm{~b}$ \\
\hline \multicolumn{6}{|l|}{ HV soil } \\
\hline Broccoli & $29.3 \mathrm{~b}$ & $15.9 \mathrm{a}$ & $34.27 \mathrm{a}$ & $7.22 \mathrm{ab}$ & $20 \mathrm{~b}$ \\
\hline No broccoli & $25.2 \mathrm{c}$ & $15.3 \mathrm{ab}$ & $19.90 \mathrm{c}$ & $3.77 \mathrm{c}$ & $60 \mathrm{a}$ \\
\hline \multicolumn{6}{|l|}{ BB soil } \\
\hline Broccoli & $31.8 \mathrm{a}$ & $16.1 \mathrm{a}$ & $34.16 \mathrm{a}$ & $8.38 \mathrm{a}$ & $20 \mathrm{~b}$ \\
\hline No broccoli & $29.0 \mathrm{~b}$ & $14.3 \mathrm{~b}$ & $26.69 \mathrm{~b}$ & $6.58 \mathrm{~b}$ & $30 \mathrm{ab}$ \\
\hline
\end{tabular}

${ }^{x} \mathrm{LV}=$ soil with $13 \mathrm{~V}$. dahliae microsclerotia per $\mathrm{g}$ of dry soil; $\mathrm{HV}=$ soil with $38 \mathrm{~V}$. dahliae microsclerotia per $\mathrm{g}$ of dry soil; and $\mathrm{BB}=$ soil with undetectable $V$. dahliae microsclerotia.

y Percentage of plants exhibiting vascular discoloration.

z Means followed by the same letter are not significantly different according to the least significant difference test $(P \leq 0.05)$. 
test $(P \leq 0.05)$. The means for $V$. dahliae root colony density and the corresponding standard errors were computed for each treatment and sampling time. The means for $V$. dahliae colonization rate per unit of soil inoculum in HV soil were calculated by dividing the colony density values by the mean number of microsclerotia from final sample (12 weeks). All analyses were done using SAS (release 6.12 ed.; SAS Institute, Cary, NC).

\section{RESULTS}

Effect on soil microsclerotial population. The means for the densities of microsclerotia population in final soil samples from cauliflower and broccoli pots within each of the soil treatments were nearly similar and, therefore, combined to compare soil treatment effects (Table 1). Furthermore, results from the two experiments were also similar. In both broccoli-amended and unamended LV and HV soils, the numbers of microsclerotia at the end of the experiment were lower than were the initial numbers. The magnitude of reduction was more than $65 \%$ in broccoli-amended soils compared with that of unamended soil. The BB soil had no detectable $V$. dahliae microsclerotia throughout the experimental runs in both cauliflower- and broccoli-planted pots.

Effect on plant growth parameters and disease severity. Cauliflower plants were significantly taller $(P \leq 0.05)$ in all soils amended with broccoli residue compared with those in controls (Table 2). Amendment with broccoli also increased the number of cauliflower leaves on LV and BB soils $(P \leq 0.05)$. Broccoli amendment also significantly $(P \leq 0.05)$ increased the height of broccoli plants and the number of leaves on LV and BB soils, but not on the HV soil (Table 3).

Cauliflower plants gained significantly $(P \leq 0.05)$ higher shoot and root biomass after broccoli residue amendment on all soils compared with that of unamended controls (Table 2). In contrast, significant $(P \leq 0.05)$ gains in broccoli root biomass occurred only on $\mathrm{BB}$ soil amended with broccoli residue compared with that of the unamended controls (Table 3). Broccoli shoot biomass was nearly identical in all treatments.

A significantly lower $(P \leq 0.05)$ percentage of cauliflower plants grown in HV soil with broccoli amendment exhibited vascular discoloration than that of plants grown without broccoli amendment (Table 2). The differences in percent vascular discoloration in other treatments in cauliflower (Table 2), as well as in all treatments in broccoli plants, were not significant $(P>0.05)$ (Table 3). Even though vascular discoloration was observed in a few broccoli plants, $V$. dahliae was not isolated from the tissues.

Effect on $V$. dahliae root colonization. Differences in colonization rates observed for the 4-, 6-, and 12-week assays were small and most were not significant. For those differences that were sig-

TABLE 3. Effect of soil treatment and broccoli amendment on broccoli growth and biomass and on Verticillium dahliae-induced vascular discoloration

\begin{tabular}{lccccc}
\hline $\begin{array}{l}\text { Treatment, } \\
\text { amendment }\end{array}$ & $\begin{array}{c}\text { Plant } \\
\text { height } \\
(\mathrm{cm})\end{array}$ & $\begin{array}{c}\text { No. of } \\
\text { leaves }\end{array}$ & $\begin{array}{c}\text { Shoot dry } \\
\text { weight } \\
(\mathrm{g})\end{array}$ & $\begin{array}{c}\text { Root dry } \\
\text { weight } \\
(\mathrm{g})\end{array}$ & $\begin{array}{c}\text { Vascular } \\
\text { discoloration } \\
(\%)^{\mathrm{y}}\end{array}$ \\
\hline LV soil & & & & & \\
$\quad$ Broccoli & $43.2 \mathrm{a}^{\mathrm{z}}$ & $10.9 \mathrm{~cd}$ & $37.70 \mathrm{a}$ & $16.96 \mathrm{ab}$ & $0 \mathrm{a}$ \\
$\quad$ No broccoli & $36.0 \mathrm{c}$ & $9.0 \mathrm{e}$ & $34.84 \mathrm{a}$ & $15.10 \mathrm{~b}$ & $0 \mathrm{a}$ \\
HV soil & & & & & \\
$\quad$ Broccoli & $38.5 \mathrm{~b}$ & $13.5 \mathrm{a}$ & $36.86 \mathrm{a}$ & $17.00 \mathrm{ab}$ & $20 \mathrm{a}$ \\
$\quad$ No broccoli & $38.4 \mathrm{~b}$ & $12.5 \mathrm{ab}$ & $35.62 \mathrm{a}$ & $16.03 \mathrm{ab}$ & $20 \mathrm{a}$ \\
BB soil & & & & & \\
$\quad$ Broccoli & $39.7 \mathrm{~b}$ & $11.4 \mathrm{bc}$ & $35.69 \mathrm{a}$ & $18.13 \mathrm{a}$ & $0 \mathrm{a}$ \\
$\quad$ No broccoli & $35.9 \mathrm{c}$ & $10.0 \mathrm{de}$ & $35.68 \mathrm{a}$ & $14.80 \mathrm{~b}$ & $10 \mathrm{a}$ \\
\hline
\end{tabular}

${ }^{x} \mathrm{LV}=$ soil with $13 \mathrm{~V}$. dahliae microsclerotia per $\mathrm{g}$ of dry soil; $\mathrm{HV}=$ soil with $38 \mathrm{~V}$. dahliae microsclerotia per $\mathrm{g}$ of dry soil; and $\mathrm{BB}=$ soil with undetectable $V$. dahliae microsclerotia.

${ }^{y}$ Percentage of plants exhibiting vascular discoloration.

${ }^{\mathrm{z}}$ Means followed by the same letter are not significantly different according to the least significant difference test $(P \leq 0.05)$. nificant, the pattern was irregular and could not be related to a temporal effect. For these reasons, mean colonization rates for the three assay dates were used to compare treatments (Fig. 1). In the LV soil, root colonization was very low and was observed only in unamended control. Colonization was not observed in the BB soil where no detectable $V$. dahliae microsclerotia were present.

Symptoms of Verticillium wilt were not observed on broccoli plants, even though $V$. dahliae colonized the surface of broccoli roots (Figs. 1 and 2C and D). Occasionally, relatively large colonies were observed (Fig. 2D). Overall, in unamended HV soil, cauliflower roots had higher counts of $V$. dahliae colonies than did broccoli (Fig. 1). There were no noticeable differences in the appearance of $V$. dahliae colonies on cauliflower roots from broccoli-amended and unamended soil treatments. The $V$. dahliae colony distribution was not specific to any particular region of the host root system. Occasionally, colonies were seen near regions where the tertiary root was emerging or near tertiary root branches (Fig. 2D and E). On cauliflower roots in unamended soil, the $V$. dahliae colonies were observed on the root apex and near the zone of root elongation (Fig. 2A), but their frequency was very rare. There was no visible damage to root hairs or to tissue near or surrounding a colony of $V$. dahliae on the root cortical surface (Fig. 2B). In all root samples from both broccoli and cauliflower plants across all treatment and sampling dates, no visible presence of microsclerotia on the root cortical surface was detected.

The immunohistochemical assay allowed us to quantitatively measure reductions in root colonization by $V$. dahliae in broccoliamended soils and compare them with that of the unamended control. Regardless of the crop, root colonization in broccoli-amended soil was $<20 \%$ of the levels observed in the unamended control in HV soils (Fig. 1). Even when adjusted for the difference in soil inoculum densities (ID), root colonization in broccoli-amended soil was less than $30 \%$ of that observed in nonamended soil (Fig. 1). When colonization rates were calculated using initial microsclerotial numbers, despite the lower colonization rates, similar trends were observed. Colonization rates per unit of inoculum were around

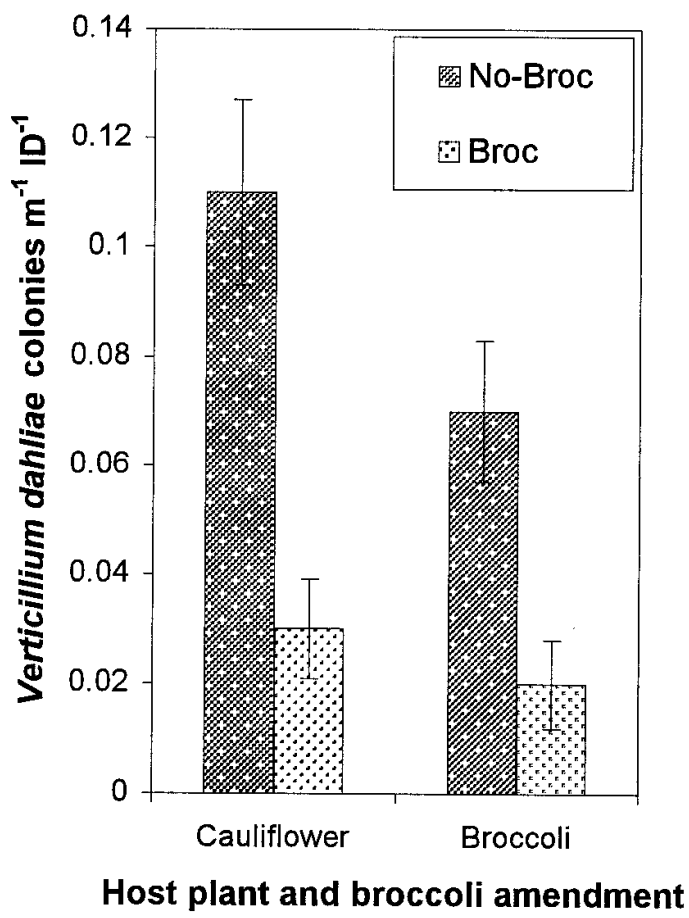

Fig. 1. Effect of broccoli amendment on Verticillium dahliae colonization of broccoli and cauliflower root cortical surface in a high-Verticillium soil ( $V$. dahliae root colony density per unit of soil inoculum). Data are means of three assays and five replications with each assay. Vertical bars represent the standard error of the mean. 
0.03 colonies per $\mathrm{m}$ per ID for amended soils and 0.1 for unamended controls (Fig. 1). V. dahliae colonization rates of cauliflower roots were, on average, 1.5-fold higher than that in broccoli (Fig. 1).

Effect on formation of microsclerotia on broccoli roots. Broccoli plants showed no symptoms of wilt at maturity. Under a stereomicroscope $(\times 10)$, microsclerotia were not detected on any of the roots. Even 60 days after removal of aboveground portions of these broccoli plants, no microsclerotia were detected on the root system that remained intact in the sand.

\section{DISCUSSION}

Broccoli residue amendment effectively reduced the incidence of Verticillium wilt of cauliflower and, consequently, improved cauliflower growth. The reduction in colony density was presum-
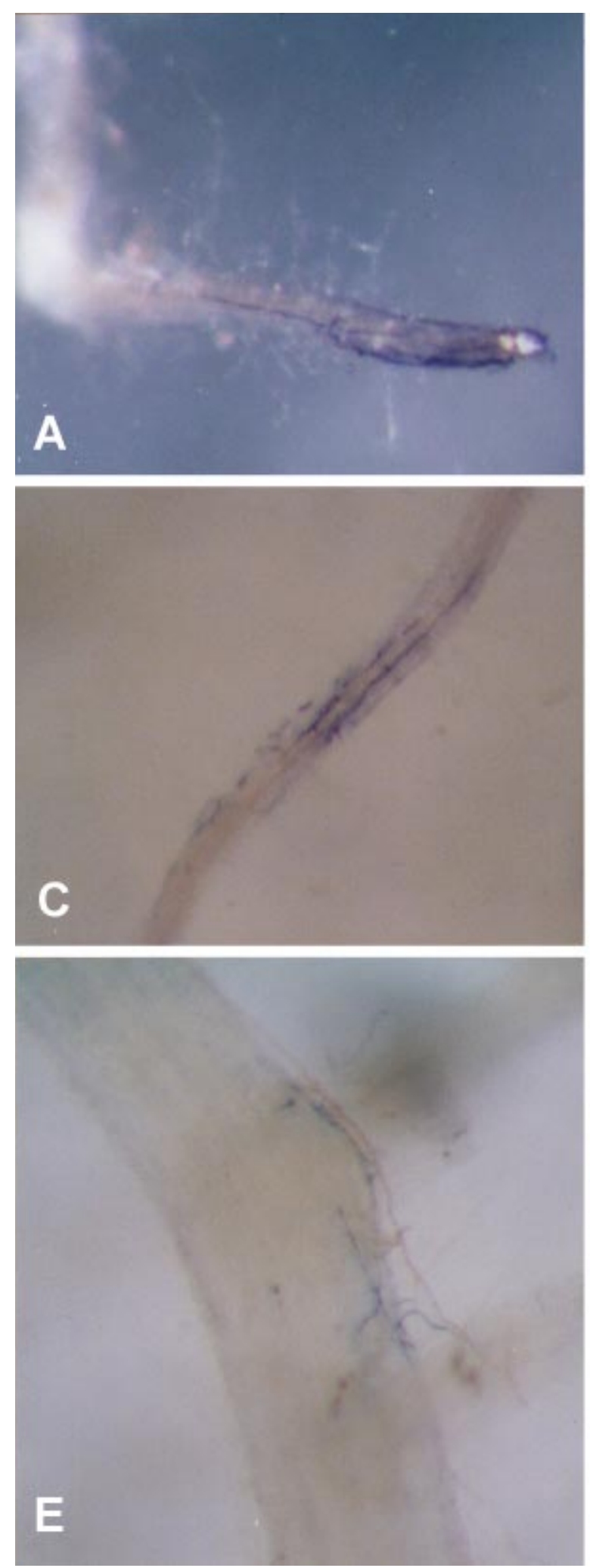

Fig. 2. A and B, Cauliflower root cortical surface showing dark blue-stained Verticillium dahliae colonies; C and D, colonies on broccoli root cortical surface (note large $V$. dahliae colonies in $\mathbf{D}$ ); and $\mathbf{E}$, stained cauliflower root cortical surface with $V$. dahliae hyphae adjacent to an unknown fungal hyphae (light brown).
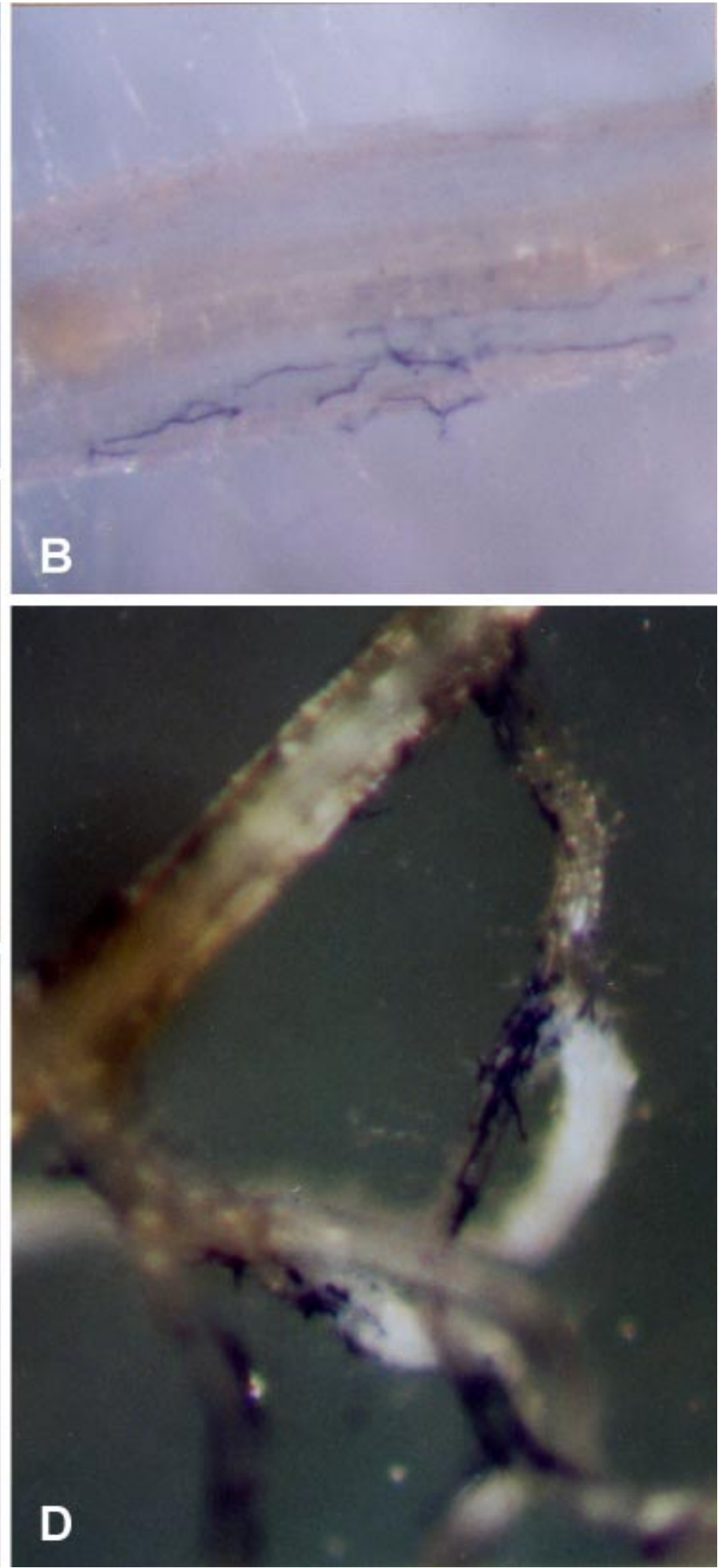
ably caused first by the reduction in the numbers of microsclerotia and subsequently by decreased root colonization potential of surviving microsclerotia under the influence of broccoli residue. A similar reduction in $V$. dahliae colony densities was observed on potato roots grown in sudan grass-amended soil (O. C. Huisman and J. R. Davis, unpublished data). The marked reduction in the numbers of $V$. dahliae microsclerotia and colony counts on cauliflower root cortical surfaces in broccoli-amended soil corroborates the previous reports of broccoli-mediated wilt reduction and growth improvement of cauliflower $(34,35,38)$.

Colonization of the root cortex by $V$. dahliae alone does not always lead to disease (10), because not all successful root infections result in colonization of the vascular tissue (15). Huisman and Gerik (17) observed that only 1 in 5,000 cortical invasions of cotton roots by $V$. dahliae results in successful vascular infection. The appearance of vascular symptoms increases with the increase in root cortical infection frequency. The chances of vascular infection may be enhanced if $V$. dahliae is able to infect at the zone of root elongation near the root apex. Since the zone near the root apex consists of tissues in their early stages of growth and maturation, it is particularly vulnerable to vascular invasion $(2,4,13)$. Furthermore, the increased root exudation near the root apex and the zone of root elongation, compared with that of the older root tissue (27), is likely to be conducive for $V$. dahliae activity. $V$. dahliae, like other colonizers, initially colonizes near the root tip $(15,18)$. However, the occurrence of $V$. dahliae colonies at the root apex is rare and almost all colonies are initiated behind the zone of elongation (17). The latter suggests that, for vascular infection, other conducive factors in addition to colonization of the root cortical surface are needed.

The low numbers of $V$. dahliae colonies observed on the cauliflower roots in broccoli-amended HV soil were unable to affect the plant biomass. In field conditions, a high percentage of cauliflower plants can show wilt symptoms even under low levels of soil microsclerotia population (37). However, the inoculum densitydisease incidence relationships can vary according to the cropping history of a field (19).

Broccoli is not susceptible to $V$. dahliae infection and does not express wilt symptoms. Thus, increases in plant growth and biomass response of broccoli following broccoli residue amendment could not be attributed to $V$. dahliae infection alone. Variations in broccoli plant growth response to inoculation with different $V$. dahliae isolates have been observed, but the extent of vascular discoloration did not always relate to the changes in biomass (R. G. Bhat and K. V. Subbarao, unpublished data). However, in other studies, inoculation with $V$. dahliae had no effect on broccoli biomass (33). Healthy crop stands of broccoli have been observed in field sites that had a very high population of microsclerotia (19). In the current study, amendment with broccoli residue stimulated a gain in root biomass of cauliflower in all soils and of broccoli in BB soil. Considering that all plants were fertilized throughout the experimental period, factors other than nutrients may have had a role.

$V$. dahliae colonizing the broccoli root cortical surface is consistent with observations of other resistant or nonhost plant species $(15,21)$. The observed colonization rates of cauliflower and broccoli roots in amended soils were similar to those observed for other hosts. Colony densities of 0.05 to 0.2 colony per $\mathrm{m}$ per ID have been observed for a wide range of plant species (15). Growth of $V$. dahliae in cortical tissue of broccoli roots, however, were lower than that in cauliflower. Occasionally, we saw extensive growth of $V$. dahliae colonies over the surface of broccoli roots, similar to that observed in other resistant plant species $(20,21)$.

Even though the cortical tissues of broccoli roots were colonized by $V$. dahliae, the infection did not progress into the vascular system. Resistance to vascular wilt pathogens in cultivars of cotton, tomato, and broccoli has been primarily attributed to cell wall reinforcement and physical localization of the pathogen (1,26,31). The potential factors at the cortex-vascular tissue interface in broccoli that prevent pathogen entry into the vascular tissue need further study.
Microsclerotia were not observed on cauliflower or broccoli roots while recording $V$. dahliae colony density. Results from the broccoli root-dip inoculation experiment confirmed the resistance of broccoli to $V$. dahliae and the absence of microsclerotia formation on its root system. In the field, however, microsclerotia are observed on infected cauliflower roots 8 weeks after harvest and removal of shoot portions (38).

Generally, most of the beneficial effects of amendments with Brassica spp. have been attributed to glucosinolates, which are sulfur-containing compounds present in all plant parts of species belonging to the family Brassicaceae (5). Glucosinolates are not toxic by themselves, but are converted to toxic isothiocyanates, thiocyanates, nitriles, epithionitriles, and oxazolidine-2-thiones as the plant tissues break down in soil (11). Allyl isothiocyanate, a breakdown product of allyl glucosinolate present in $B$. juncea, completely suppresses in vitro radial growth of $V$. dahliae (24). In vitro studies with broccoli tissue extract incorporated into media were not inhibitory to the growth of $V$. dahliae (K. V. Subbarao, unpublished data). Furthermore, the number of $V$. dahliae cortical infections in cauliflower and broccoli along with the significant sizes of these colonies suggest that glucosinolates may not play a significant role in the prevention of cortical tissue colonization.

Although glucosinolate decomposition products have been observed in soil amended with brassica tissue, the volatile antifungal components released $(12,22,24)$ are transient and may only have a limited role. Results from recent studies on rotation crop residue amendment suggest a biological mode of action; sustained suppression of soilborne pathogens results from the activation of biological components that are already present in the soil $(9,29,32$, $35)$. In the rhizosphere, any stages of the pathogen life cycle could be susceptible to the biological suppressive components in a number of ways. It is plausible that the microbial population changes resulting from broccoli residue decomposition also lead to greatly increased competition among root colonizers. Increased microbial activity following broccoli amendment (K. V. Subbarao, unpublished data) and the resulting competition for colonization of root cortical surface may also limit infection foci for $V$. dahliae.

The biological suppressive action may result from the effects of compounds released from the residue or of the decomposition products on population density and activity of antagonistic microorganisms $(9,23,25)$. Mature broccoli crop residues are rich in lignin, and the enzymes involved in lignin biodegradation can also degrade fungal melanin (6). Melanin is known to protect the fungus from various abiotic and biotic stresses (7), and the microsclerotium of $V$. dahliae is a melanized structure; therefore, it can be hypothesized that biodegradation of broccoli residues may also affect $V$. dahliae microsclerotia. Earlier reports of Verticillium wilt suppression have been correlated with soil manganese and zinc content $(3,9)$. Manganese is an important component of ligninolytic enzyme complex. Although the relationship between melanolytic activity and the actual antagonism toward $V$. dahliae was observed to be weak (30), the loss of melanin may render the fungus more susceptible to microbial antagonists. Investigations are under way to study the broccoli rhizosphere effects on the selection and activities of microbial antagonists.

In summary, results from this study substantiate field studies in which broccoli rotation and residue incorporation into the soil were observed to be effective in reducing $V$. dahliae populations in the soil. Broccoli residue amendment had a negative impact on the root colonization potential of $V$. dahliae in both broccoli and cauliflower and on cauliflower wilt incidence. The results with BB soil show a complete absence of any detectable $V$. dahliae microsclerotia in soil or colonies on broccoli or cauliflower roots. Broccoli rotation, which is compatible with existing cropping systems in the Salinas Valley, is effective in reducing the inoculum and, consequently, the disease incidence. The role of broccoli crops as a potential "trap host" to $V$. dahliae and its role in inoculum depletion in soil needs further investigation. 


\section{LITERATURE CITED}

1. Beckman, C. H. 1968. An evaluation of possible resistance mechanisms in broccoli, cotton, and tomato to vascular infection by Fusarium oxysporum. Phytopathology 58:429-433.

2. Beckman, C. H., and Talboys, P. W. 1981. Anatomy of resistance. Pages 487-521 in: Fungal Wilt Diseases of Plants. M. E. Mace, A. A. Bell, and C. H. Beckman, eds. Academic Press Inc., New York.

3. Bell, A. A. 1973. Nature of disease resistance. Page 52 in: Verticillium Wilt of Cotton. USDA Pub. ARS-S-19. Southern Region, New Orleans.

4. Bowers, J. H., Reidel, R. M., and Rowe, R. C. 1992. Infection of potato root tips by Verticillium dahliae as affected by Pratylenchus penetrans and P. crenatus. (Abstr.) Phytopathology 82:1089.

5. Brown, P. D., and Morra, M. J. 1997. Control of soil-borne plant pests using glucosinolate-containing plants. Pages 167-231 in: Advances in Agronomy. D. L. Sparks, ed. Academic Press, San Diego, CA.

6. Butler, M. J., and Day, A. W. 1998. Destruction of fungal melanins by ligninases of Phanerochaete chrysosporium and other white rot fungi. Int. J. Plant Sci. 159:989-995.

7. Butler, M. J., and Day, A. W. 1998. Fungal melanins: A review. Can. J. Microbiol. 44:1115-1136.

8. Butterfield, E. J., and DeVay, J. E. 1977. Reassessment of soil assays for Verticillium dahliae. Phytopathology 67:1073-1078.

9. Davis, J. R., Huisman, O. C., Westermann, D. T., Hafez, S. L., Everson, D. O., Sorensen, L. H., and Schneider, A. T. 1996. Effects of green manure on Verticillium wilt of potato. Phytopathology 86:444-453.

10. Evans, G., and Gleeson, A. C. 1973. Observations on the origin and nature of Verticillium dahliae colonizing plant roots. Aust. J. Biol. Sci. 26:151-161.

11. Fenwick, G. R., Heaney, R. K., and Mullin, W. J. 1983. Glucosinolates and their breakdown products in food and food plants. CRC Crit. Rev. Food Sci. Nutr. 18:123-201.

12. Gamliel, A., and Stapleton, J. J. 1993. Characterization of antifungal volatile compounds evolved from solarized soil amended with cabbage residues. Phytopathology 83:899-905.

13. Garber, R. H., and Houston, B. R. 1966. Penetration and development of Verticillium albo-atrum in the cotton plant. Phytopathology 56:1121-1126.

14. Gerik, J. S., and Huisman, O. C. 1988. Study of field-grown cotton roots infected with Verticillium dahliae using an immunoenzymatic staining technique. Phytopathology 78:1174-1178.

15. Huisman, O. C. 1988. Seasonal colonization of roots of field-grown cotton by Verticillium dahliae and V. tricorpus. Phytopathology 78:708-716.

16. Huisman, O. C. 1988. Colonization of field-grown cotton roots by pathogenic and saprophytic soilborne fungi. Phytopathology 78:716-722.

17. Huisman, O. C., and Gerik, J. S. 1989. Dynamics of colonization of plant roots by Verticillium dahliae and other fungi. Pages 1-17 in: Vascular Wilt Diseases of Plants: Basic Studies and Control. E. C. Tjamos and C. H. Beckman, eds. Springer-Verlag KG, Berlin.

18. Isaac, I. 1946. Verticillium wilt of Sainfoin. Ann. Appl. Biol. 33:28-34.

19. Koike, S. T., Subbarao, K. V., Davis, R. M., Gordon, T. R., and Hubbard, J. C. 1994. Verticillium wilt of cauliflower in California. Plant Dis. 78: 1116-1121.

20. Lacy, M. L., and Horner, C. E. 1966. Behavior of Verticillium dahliae in the rhizosphere and on roots of plants susceptible, resistant, and immune to wilt. Phytopathology 56:422-430.

21. Leavy, J., and Isaac, I. 1976. Colonization of host tissue of varying resistance to Verticillium dahliae. Trans. Br. Mycol. Soc. 67:91-94.

22. Lewis, J. A., and Papavizas, G. C. 1970. Evolution of volatile sulfurcontaining compounds from decomposition of crucifers in soil. Soil Biol. Biochem. 2:239-246.

23. Lockwood, J. L. 1988. Evolution of concepts associated with soilborne plant pathogens. Annu. Rev. Phytopathol. 26:93-121.

24. Mayton, H. S., Olivier, C., Vaughn, S. F., and Loria, R. 1996. Correlation of fungicidal activity of Brassica species with allyl isothiocyanate production in macerated leaf tissue. Phytopathology 86:267-271.

25. Papavizas, G. C. 1963. Microbial antagonists in bean rhizosphere as affected by oat straw and supplemental nitrogen. Phytopathology 53:1430-1435.

26. Robb, J., Powell, D. A., and Street, P. F. S. 1989. Vascular coating: A barrier to colonization by the pathogen in Verticillium wilt of tomato. Can. J. Bot. 67:600-607.

27. Rovira, A. D. 1969. Plant root exudates. Bot. Rev. 35:35-57.

28. Schnathorst, W. C. 1981. Life cycle and epidemiology of Verticillium. Pages 81-111 in: Fungal Wilt Diseases of Plants. M. E. Mace, A. A. Bell, and C. H. Beckman, eds. Academic Press, Inc., New York.

29. Scholte, K., and Lootsma, M. 1998. Effect of farmyard manure and green manure crops on populations of mycophagous soil fauna and Rhizoctonia stem canker of potato. Pedobiologia 42:223-231.

30. Shetty, K. G., and Subbarao, K. V. 1999. Melanolytic activity of microorganisms and antagonism to Verticillium dahliae. (Abstr.) Phytopathology 89(suppl.):S72.

31. Smit, F., and Dubery, I. A. 1997. Cell wall reinforcement in cotton hypocotyls in response to a Verticillium dahliae elicitor. Phytochemistry 44: 811-815

32. Stapleton, J. J., and Duncan, R. A. 1998. Soil disinfestation with cruciferous amendments and sublethal heating: Effects on Meloidogyne incognita, Sclerotium rolfsii and Pythium ultimum. Plant Pathol. 47:737742 .

33. Subbarao, K. V., Chassot, A., Gordon, T. R., Hubbard, J. C., Bonello, P., Mullin, R., Okamoto, D., Davis, R. M., and Koike, S. T. 1995. Host range of Verticillium dahliae from cauliflower and genetic relationships and cross pathogenicities of isolates from different crops. Phytopathology 85:1105-1112.

34. Subbarao, K. V., and Hubbard, J. C. 1996. Interactive effects of broccoli residue and temperature on Verticillium dahliae microsclerotia in soil and on wilt in cauliflower. Phytopathology 86:1303-1309.

35. Subbarao, K. V., Hubbard, J. C., and Koike, S. T. 1999. Evaluation of broccoli residue incorporation into field soil for Verticillium wilt control in cauliflower. Plant Dis. 83:124-129.

36. Tennant, D. 1975. A test of a modified line intersect method of estimating root length. J. Ecol. 63:995-1001.

37. Xiao, C. L., and Subbarao, K. V. 1998. Relationship between Verticillium dahliae inoculum density and wilt incidence, severity, and growth of cauliflower. Phytopathology 88:1108-1115.

38. Xiao, C. L., Subbarao, K. V., Schulbach, K. F., and Koike, S. T. 1998. Effects of crop rotation and irrigation on Verticillium dahliae microsclerotia in soil and wilt in cauliflower. Phytopathology 88:1046-1055. 